\title{
The Challenges and Opportunities of Medical Physics during the Transformation Period of Independent Medical Colleges
}

\author{
Benchao Zhu ${ }^{1,2, a^{*}}$, Weiwei Jiang ${ }^{3, b}$ and Fan Zhang ${ }^{3, c}$ \\ ${ }^{1}$ Institute of Medicine and Nursing, Hubei University of Medicine, Shiyan 442000, China \\ ${ }^{2}$ Hubei University of Medicine, Shiyan 442000, China \\ ${ }^{3}$ Hubei Dongfeng Automobile Technician College, Shiyan 442000, China \\ azbc@hbmu.edu.cn, bjww0507@163.com, ${ }^{\mathrm{c}} 326386321$ @qq.com
}

Keywords: Transformation; Application and technical; Independent medical colleges; Medical physics course; Challenges and opportunities

\begin{abstract}
Ministry of education of the People's Republic of China put forward a policy of guiding some ordinary colleges and universities to the application and technical. Under this background, all the independent medical colleges positively respond to the transformation policy. Firstly, this paper analyzes the reason why this kind of transformation is welcomed in independent medical colleges. Then, the challenges and difficulties of Medical Physics Teaching during the transformation period of independent Medical Colleges are presented. Finally, the conclusion is that, the transformation of independent medical colleges will also bring some opportunities to medical physics courses.
\end{abstract}

\section{Introduction}

In 2014, one of the educational reform policies put forwarded by the Ministry of education of the People's Republic of China is to build a modern vocational education system. For higher education, the specific measures are to guide some ordinary colleges and universities to the application and technical colleges and universities [1,2]. After more than three years of independent medical colleges restructuring and adjustment, the different courses teaching situation vary greatly. Many medical professional course teaching, like surgery, biochemistry, pathology, and so on, not only the theory teaching, but also the experimental teaching, have been strengthened. But many common public basic courses teaching, like medical mathematics, medical physics and medical chemistry, have been weakened in all aspects. Worse still, the weakened teaching of the above public basic courses make them in trouble [3]. In the consideration of the real purpose of the Ministry of education's higher colleges' transformation policy, one can safely conclude that, whether it is a medical professional course or a public basic course, each course can play its own function in the process of the transformation of the medical independent college. In other words, although, the policy of the transformation of the medical independent college will challenge the existing teaching effect of medical physics course, but it will also bring new opportunities for the reform of teaching.

In this paper, we will present three aspects of medical physics teaching situation. First, what situation did medical physics face, e. g, what is the transformation policy of independent medical colleges. Second, why this transformation make medical physics course teaching in trouble? And finally, what opportunities of medical physics course can be found in the transformation period of the independent medical colleges?

The current situation of independent medical colleges in China. As we know, after 1949, especially after 1979, the rapid development of China's Higher Education caused that, Nation's colleges and universities increased significantly. There are two types of universities in China's Higher Education, state funded universities and Non-government funded colleges (or independent colleges). The state-owned universities or colleges can be divided into two kind, one is directly managed by the Ministry of education, and the other is the management of the local education department. Until 2014, 
there are nearly 1200 institutions of higher education in China, and only 22 independent medical colleges, which can be seen in the Table 1 below, in the total 338 independent colleges [4].

Table 1 List of independent medical college

\begin{tabular}{|l|l|c|l|l|}
\hline 1 & $\begin{array}{l}\text { Xiangxing College of Hunan university } \\
\text { of Chinese Medicine (Changsha, } \\
\text { Hunan) }\end{array}$ & 12 & $\begin{array}{l}\text { Houbo College of Xinjiang Medical } \\
\text { University (Urumchi, Xinjiang) }\end{array}$ \\
\hline 2 & $\begin{array}{l}\text { Clinical medicine college of Chinese } \\
\text { medical University (Benxi, Liaoning) }\end{array}$ & 13 & $\begin{array}{l}\text { Jinci College of Shanxi Medical } \\
\text { University (Taiyuan, Shanxi) }\end{array}$ \\
\hline 3 & $\begin{array}{l}\text { Zhongshan College of Dalian Medical } \\
\text { University (Dalian, Liaoning) }\end{array}$ & 14 & $\begin{array}{l}\text { Clinical College of Anhui Medical } \\
\text { University (Hefei, Anhui) }\end{array}$ \\
\hline 4 & $\begin{array}{l}\text { Medical College of Liaoning Medical } \\
\text { College (Jingzhou, Liaoning) }\end{array}$ & 15 & $\begin{array}{l}\text { Shizheng College of Guiyang Chinese } \\
\text { Medicine College (Guiyang, Guizhou) }\end{array}$ \\
\hline 5 & $\begin{array}{l}\text { Xinglin College of Liaoning University } \\
\text { of Chinese Medicine (Shenyang, } \\
\text { Liaoning) }\end{array}$ & 16 & $\begin{array}{l}\text { Medicine and Technology of Zunyi } \\
\text { Medical Medicine (Zunyi, Guizhou) }\end{array}$ \\
\hline 6 & $\begin{array}{l}\text { Institute of Medicine and Nursing, } \\
\text { Hubei University of Medicine (Shiyan, } \\
\text { Hubei) }\end{array}$ & 17 & $\begin{array}{l}\text { Shenqi Ethnic College of Guizhou } \\
\text { Medical University (Guiyang, Guizhou) }\end{array}$ \\
\hline 7 & $\begin{array}{l}\text { Binjiang College of Zhejiang Chinese } \\
\text { Medicine University (Hangzhou, } \\
\text { Zhejiang) }\end{array}$ & 18 & $\begin{array}{l}\text { Clinical College of Tianjing Medical } \\
\text { University (Tianjing) }\end{array}$ \\
\hline 8 & $\begin{array}{l}\text { Renji College of Wenzhou University } \\
\text { of Medicine (Wenzhou, Zhejiang) }\end{array}$ & 19 & $\begin{array}{l}\text { Nanjing University of Chinese Medicine } \\
\text { Hanlin College (Nanjing, Jiangshu) }\end{array}$ \\
\hline 9 & $\begin{array}{l}\text { Clinical College of Hebei Medical } \\
\text { University (Shijiazhuang, Hebei) }\end{array}$ & 20 & $\begin{array}{l}\text { Haiyuan College of Kunming Medical } \\
\text { University (Kunming, Yunnan) }\end{array}$ \\
\hline 10 & $\begin{array}{l}\text { Ji Tang College of North China } \\
\text { University of science and technology } \\
\text { (Tangshan, Hebei) }\end{array}$ & 21 & $\begin{array}{l}\text { Faculty of Chinese Medicine Science } \\
\text { Guangxi university of Chinese medicine } \\
\text { (Nanning, Guangxi) }\end{array}$ \\
\hline 11 & $\begin{array}{l}\text { Sanquan College of Xinxiang Medical } \\
\text { University (Xinxiang, Henan) }\end{array}$ & 22 & $\begin{array}{l}\text { Science and Technology College of } \\
\text { Jiangxi Chinese medical University } \\
\text { (Nanchang, Jiangxi) }\end{array}$ \\
\hline
\end{tabular}

As the Table 1 shows that only eight independent medical schools are located in non provincial capitals. Limited national admissions policies and the city's economic, demographic and other factors, these independent medical colleges must be distinguished from the general colleges and Universities.

The policy of transformation of higher education and its specific forms in the independent medical colleges. The purpose of the transformation policy of higher education is easy to understand, when taking into account the comprehensive development of the country and improve the penetration rate of higher education, a small number of colleges and universities should be built into an academic type, while the other must be applied and skilled colleges and Universities. Obviously, the independent medical colleges should be marked as the application type colleges [5]. So, all the independent medical colleges actively responded to the Ministry of education reform policy. Specifically, in addition to the basic features of higher education, independent medical colleges must attach importance to the cultivation of students' skills.

For Clinical specialty, the common practice is to increase student learning in hospital. Diagnosis and treatment of more common diseases through long clinical probation. After paying attention to skills training, the quality of clinical professional theory of independent medical colleges' graduates may be reduced, but they can directly competent community hospitals, county hospitals, etc. In other words, the application type medical college graduates do not need too much theoretical basis, but only requires the operation skills, which can solve the specific general problems. For complex problems, they can be transferred to a higher level hospital for treatment. 
For medical imaging specialty, shorten the professional education period from 5 years to 4 years, and then, awarding students Bachelor of Science degree but not Bachelor of Medicine degree. An important result is that this type of imaging doctors do not have the right to diagnosis, they can only operate medical imaging equipment based on their knowledge of medicine.

For medical rehabilitation specialty, the usually way is to weaken the learning of rehabilitation principle, and strengthen the rehabilitation skills, like the use of medical massage, medical rehabilitation equipment and rehabilitation psychology and so on.

Before ending this section, in the consideration of the level of undergraduate skills, it must be emphasized that the above orientation of the skill training of independent medical colleges is absolutely different from that of Vocational Education.

The challenges of medical physics course during the transformation period of independent medical colleges. As the above section shows that, many medical professional course teaching, like surgery, biochemistry, pathology, and so on, not only the theory teaching, but also the experimental teaching, have been strengthened. Accordingly, under the premise that the total teaching period is unchanged or even shorter. Some other common public basic courses teaching, like medical mathematics, medical physics and medical chemistry, will be absolutely weakened in all aspects. Worse still, the weakened teaching of the above public basic courses make them in trouble. Specifically, the medical physics course faced two challenges:

i) Is it necessary to retain the medical physics course in the transformation period of independent medical colleges [6]? Physics is the study of the laws of motion and the basic structure of matter. Medicine is a science or technology that deals with the various diseases and disorders of the human body. Medical physics is the application of the principles and methods of physics to the prevention, diagnosis, treatment and health care of human diseases. Medical physics seems to provide more theoretical support, not professional skill support for medical students, and this is also the main reason for the difficulty of the teaching of Medical Physics course. Worse still, as the Table 1 shows in the above section, the scale and region of independent medical colleges' make them must save teaching costs as a prerequisite, and enhance the competitiveness of students. The medical physics course is the brunt of the impact, and thus, whether it is necessary to preserve the course of medical physics is a challenging problem.

ii) If respected the basic principles of Higher Education [7], so that retain the medical physics course. How to exert the function of skill training in medical physics course? Physics is an experimental subject, it seems that there is a certain relationship between experiment and skill. However, the physical experiment is a scientific experiment, for example, the verification experiment of classical physics theory. But the medical skills require hands-on experience of actual cases. So, medical skills and physical experiments are obviously different. Under the premise of not increasing education funds, How to exert the function of skill training in medical physics course is a challenging problem.

The opportunities of medical physics course during the transformation period of independent medical colleges. As we all know that, a coin has two sides, and opportunities are often bred in difficulties. Medical physics course teaching, not only theory, but also experiment, can make some contribution to medical skills training. Firstly, in the Ref. [8], based on the basic principles of pedagogy and the relationship between physics and medicine, we have solved the problem of whether it is necessary to preserve the course of medical physics in medical colleges. The remaining problem is to demonstrate that, medical skills training actually provide opportunities for Medical Physics Teaching. It should be emphasized that this paper discusses the relationship between the teaching of medical physics and the training of medical skills. From the traditional teaching methods and teaching rules, in the process of the transformation of independent medical colleges, medical physics can provide limited skills training. In order to meet the medical skills training, we must break some routine:

i) There is no need to retain the integrity of medical physics, which does not follow common rule of the fundamentals of mechanics, fluid mechanics, molecular dynamics, thermodynamics, electromagnetics, optics, atomic physics, and modern physics. For the physical content related to medical skills, we can even ignore the theoretical derivation and the theoretical rigor. For example, the effect of blood viscosity on blood pressure in hypertensive disorders, ignoring how to get Poisson's 
formula, just through blood viscosity experiment, which can help medical students understanding why Hypertension drugs need to expand the function of blood vessels, and the physical causes of cardiac stent technique.

ii) The theory and experiment teaching of medical physics can be integrated into the basic medical courses, so as to break the boundaries of current traditional curriculums. Under the premise of not considering the integrity of the medical physics course, the significance of the existence of a separate medical physics course can be blurred, but it does not mean that the physics course can be deleted. For different medical specialties, different physics theories and experiments can be selected to embed in professional medical courses. For example, clinical medicine specialty needs lots of theories and experiments of fluid mechanics and mechanics. Medical rehabilitation specialty needs lots of knowledge of elastic mechanics and electromagnetics. Medical imaging specialty needs more modern physics theories and experiments. The re-integration of content will help reducing duplication between similar disciplines.

iii) Using the modern teaching methods, such as micro lesson and MOOC [9], to reduce the students' study time. On the basis of not increasing the burden of students, new teaching methods can stimulate students' studying interest. With the help of the network, we can share the medical physics video resources and strengthen the students' connection to the physical and medical skills.

The new course of medical physics, as well as a variety of teaching content, coupled with new teaching methods and Internet technology, all these changes of medical physics course come from the transformation policy of independent medical colleges. This is why we conclude the transformation period of independent medical colleges provides opportunities to medical physics course.

\section{Summary}

In this paper, we firstly introduce the current situation of independent medical colleges in China. Then analyzing the policy of transformation of higher education and its specific forms in the independent medical colleges. Finally, what are the challenges and opportunities of medical physics course during the transformation period of independent medical colleges also presented.

\section{Acknowledgements}

This work is supported by the Institute of Medicine and Nursing, Hubei University of Medicine, 2016 teaching research project fund, N0. YHJ2016014.

\section{References}

[1] Dong HL. Right time to transformation of local undergraduate colleges (Education vision focusing on the transformation of undergraduate colleges (I)), People's daily, May 8, 2014, eighteenth edition: Education weekly.

[2] Dong HL. How to transformation of local undergraduate colleges (Education vision - focusing on the transformation of undergraduate colleges (II)), People's daily, May 8, 2014, eighteenth edition: Education weekly.

[3] Fang $\mathrm{Wu}$, Discussion on the current situation of personnel training and the improvement of training quality in Independent Colleges, Journal of Huanghe S\&T University, 2016, 18 (5) 6-10.

[4] Information on http://www.edu.cn.

[5] Zheng-Qiang Wang, Wan-Guo He, Zong-Mo Cai, The development of Independent Colleges in China: present situation, difficulties and solutions, Higher Agricultural Education. 2017, (1) 15-18

[6] Tan Xiaoling, Teaching reform and exploration of Medical Physics, Journal of Higher Education, 2016 (2) 122-123

[7] Shan Ying, Min Ji, Theory of Higher Education ( $1^{\text {th }}$ Edition), Education Science Press, Bei Jing, 2008. 
[8] B Zhu , W Jiang, F Zhang, The Study on the Necessity of Learning Medical Physics in Local Medical University in the Policy of the University Transformation, International Conference on Education , 2016.

[9] Ye Liying, Yang Qiong, Liu Limei, Research on the feasibility of "MOOC" in the teaching of Medical Physics, Biotech world, 2016 (5) 299-299. 